\title{
Identifying factors for job motivation of rural health workers in North Viet Nam
}

\author{
Marjolein Dieleman*1, Pham Viet Cuong2, Le Vu Anh ${ }^{2}$ and Tim Martineau ${ }^{3}$
}

Address: ${ }^{1}$ Royal Tropical Institute, Amsterdam, The Netherlands, ${ }^{2}$ Hanoi School of Public Health, Hanoi, Viet Nam and ${ }^{3}$ Liverpool School of Tropical Medicine, Liverpool, United Kingdom

Email: Marjolein Dieleman* - m.dieleman@kit.nl; Pham Viet Cuong - pvc1@hsph.edu.vn; Le Vu Anh - hsph@fpt.vn; Tim Martineau - t.martineau@liverpool.ac.uk

* Corresponding author

Published: 05 November 2003

Human Resources for Health 2003, I:10
Received: 17 October 2003

Accepted: 05 November 2003

This article is available from: http://www.human-resources-health.com/content/l/1/10

(C) 2003 Dieleman et al; licensee BioMed Central Ltd. This is an Open Access article: verbatim copying and redistribution of this article are permitted in all media for any purpose, provided this notice is preserved along with the article's original URL.

\begin{abstract}
Background: In Viet Nam, most of the public health staff (84\%) currently works in rural areas, where $80 \%$ of the people live. To provide good quality health care services, it is important to develop strategies influencing staff motivation for better performance.

Method: An exploratory qualitative research was carried out among health workers in two provinces in North Viet Nam so as to identify entry points for developing strategies that improve staff performance in rural areas. The study aimed to determine the major motivating factors and it is the first in Viet Nam that looks at health workers' job perception and motivation. Apart from health workers, managers at national and at provincial level were interviewed as well as some community representatives.

Results: The study showed that motivation is influenced by both financial and non-financial incentives. The main motivating factors for health workers were appreciation by managers, colleagues and the community, a stable job and income and training. The main discouraging factors were related to low salaries and difficult working conditions.

Conclusion: Activities associated with appreciation such as performance management are currently not optimally implemented, as health workers perceive supervision as control, selection for training as unclear and unequal, and performance appraisal as not useful. The kind of nonfinancial incentives identified should be taken into consideration when developing HRM strategies. Areas for further studies are identified.
\end{abstract}

\section{Introduction}

Many Ministries of Health are trying to improve the functioning of their health care system by introducing changes in resource allocation, better management and changes in the role of the government, such as more responsibility at lower levels through decentralisation. A prerequisite of a well-functioning system is a well-motivated workforce. The Ministry of Health in Viet Nam gives great importance to the development of a public health network, in order to provide good quality health care services. As most people live in rural areas, an extensive public health network is required in rural areas so as to provide appropriate care close to the people. This implies the need to keep sufficient qualified and motivated human resources in the rural areas. 
In the work context motivation can be defined as an individual's degree of willingness to exert and maintain an effort towards organisational goals [1]. Motivation is a complex concept and many theories exist that describe and analyse workers' motivation. Summarised, motivation of staff is determined by factors at various levels [2]:

- at an individual level, factors such as a person's job expectations, his or her self-esteem to be able to do a certain job and his/her own goals compared to the goals of the organisation.

- at an organisational level, at which two types of motivation can be distinguished according to Herzberg's theory of motivation at the workplace $[2,3]$ :

- Motivation to accept and to remain at a post, which is related to meeting needs of job security, salary, etc. An organisation or institute can attract and keep personnel in their post through salaries, allowances and working conditions, such as the availability of equipment, and communication and relationship with colleagues. If the salaries and working conditions are unsatisfactory (for example, salaries do not cover the basic needs), health workers are likely to find ways to compensate for this. For instance, they will become more concerned with earning enough to cover their basic needs in other ways than to work hard for their public service post. In Herzberg's theory these are called "factors for dissatisfaction (dissatisfiers)". These dissatisfiers are mainly extrinsic factors.

- Motivation to improve performance is linked to a feeling of self-fulfilment, achievement and recognition [2,3]. These feelings can be influenced by effective performance management, through which managers ensure that staff is competent and motivated in their job [4]. It involves supervision, training, performance appraisal and career development. These satisfiers (or 'motivators') are based on intrinsic motivation.

- at the larger socio-cultural level, motivating factors such as the relationships between health workers and clients, support from community leaders and perception of community members with respect to services.

Theories about motivation are, mostly, based on studies focusing on the private sector. To some extent motivation studies have been conducted in the public sector in developed countries [5]. Little is known about the motivational factors that are important for health workers in developing countries [2]. As the Ministry of Health gives importance to a public health network in rural areas in Viet Nam, knowledge on motivation of staff working in rural areas seems important. However, in Viet Nam little research has been conducted that document perspectives of health workers - at commune and district level in rural areas - on HRM factors influencing their motivation. Gaining a better insight in the way these health workers perceive their jobs and the importance they give to the various influences on their motivation will assist in developing strategies for improving performance of health workers in rural areas.

In order to identify strategies to assist the Ministry of Health to motivate staff working in the public health network in rural areas, the Hanoi School of Public Health and the Royal Tropical Institute (KIT) conducted a study. The study aimed to describe the main factors influencing job motivation at commune and district health centres in rural areas of North Viet Nam and to recommend ways for improving motivation of health workers. The study looked at the relation between the implementation of various HRM tools in Viet Nam and the perception of health workers of these tools on their motivation.

Herzberg's theory for motivation at the workplace [6] was used as a basis for the study design. This model assists in clarifying the complex issue of motivation for health workers. The two-factor theory distinguishes between motivating factors (or 'satisfiers') that are intrinsic to the job and the primary causes of job satisfaction, and dissatisfiers (which Herzberg also calls 'hygiene factors') that are extrinsic to the job and the primary causes of job dissatisfaction, or "unhappiness on the job". Job satisfaction and job dissatisfaction are not opposites. Motivating factors include: "achievement, recognition for achievement, the work itself, responsibility, and growth or advancement" and lead to job satisfaction. Their absence leads to lack of job satisfaction. Dissatisfiers include: "company policy and administration, supervision, interpersonal relationships, working conditions, salary, status, and security" and determine the level of job dissatisfaction. Herzberg found that many of the dissatisfiers had a small effect on job satisfaction e.g. supervision; likewise some motivating factors reduced job dissatisfaction to some extent e.g. achievement.

The relevance of Herzberg's theory for Human Resources Management (HRM) is the need to clarify whether the problem being addressed is mainly one of job satisfaction or one of job dissatisfaction, and then to select the appropriate personnel management strategies. For example attending to salary levels and working conditions will primarily reduce job dissatisfaction and therefore increase staff retention. To improve motivation and thereby increase staff performance, attention should be given to motivating factors, for example by increasing the individual's sense of achievement and to demonstrate recognition of that achievement. 


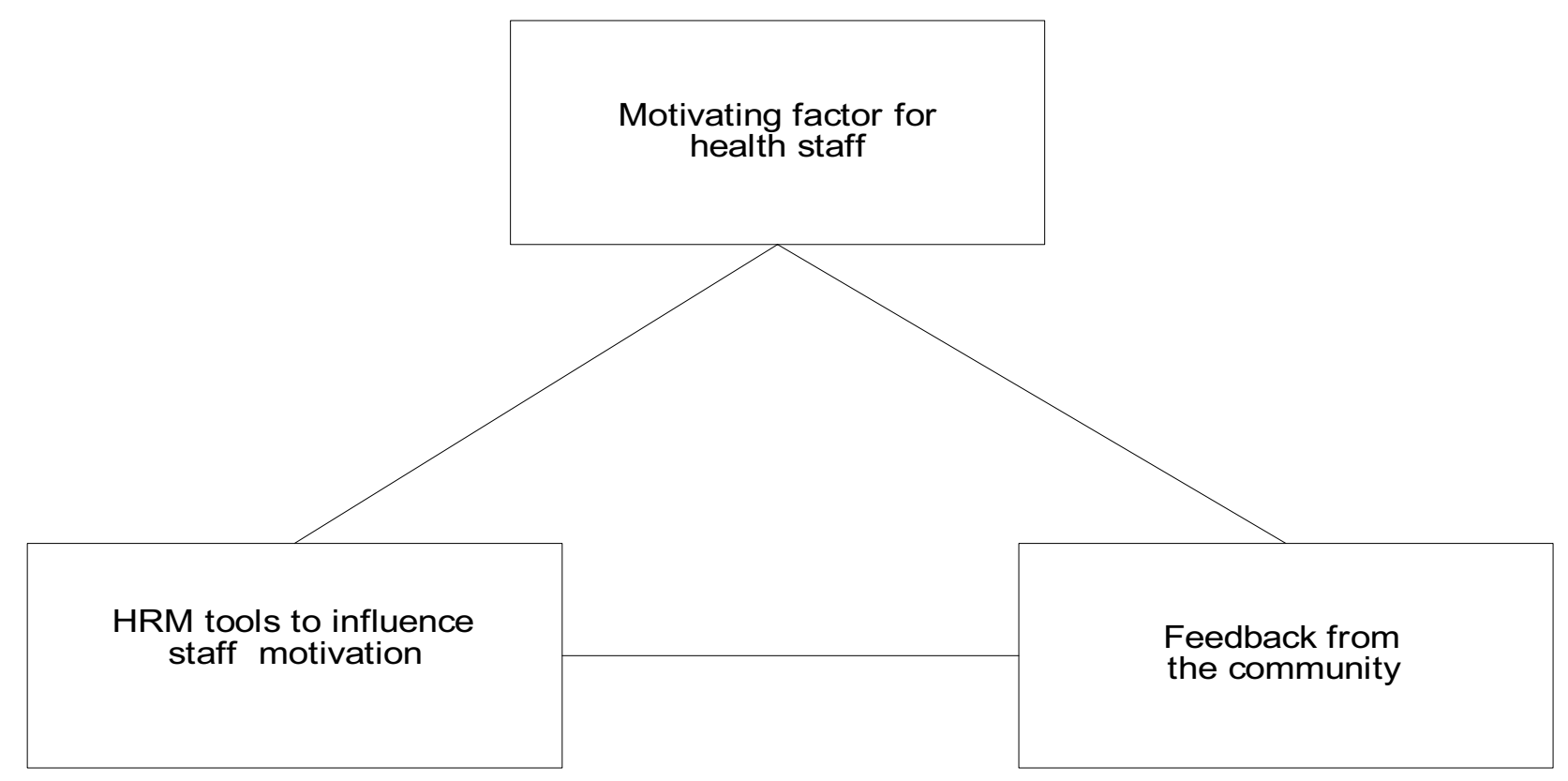

Figure I

Approach to the study.

Another important element for staff motivation, especially in rural areas, could be feed back from the community. This could play an important role with respect to recognition and achievement, especially when supervision is not frequent and feed back from colleagues and managers is lacking. Although feed back from the community is not an adequate substitute for professional appreciation of service delivery of staff, reactions from clients on the service they received can help staff in assessing if their services are 'job satisfiers' and motivate them to put more effort in service delivery.

The link between the main elements of the study is shown in Fig. 1.

The application and the value attached to the use of the different HRM tools and to feedback from the community will probably depend on the socio-cultural environment people work and live in. The study in Viet Nam assessed the match (or mismatch) health workers perceive between the factors they perceive as motivating and discouraging in their work and the implementation of HRM tools. In addition, it looked at the relation between the community and the health workers. The research results will be used to improve HRM training for health managers and pro- vide information for the development of Human Resources Development (HRD) policies.

\section{Background}

Health system in Viet Nam [7]

The health system in Viet Nam has four tiers, as shown in Fig. 2. At village level the policy is to have one volunteer Village Health Worker (VHW) in each village. (Villages are administrative subunits of communes, and are often separated by agricultural areas. Villages can be quite widely scattered in remote areas and be quite far from the $\mathrm{CHC}$.) These volunteers are members of the community who receive training from the provincial health service, often at the district level, to cope with the most common medical needs of the population of the village. Currently an extensive network of volunteer health workers in the villages exists, about $52 \%$ of all villages in Viet Nam have a VHW [8].

\section{Staff in the public health sector}

Health workers working in public health in rural areas face many difficulties. Salaries of public health personnel are very low, averaging US\$29 per month. Although allowances are provided for various kinds of tasks or for the implementation of projects, it remains difficult to survive just on the income. Therefore most health 


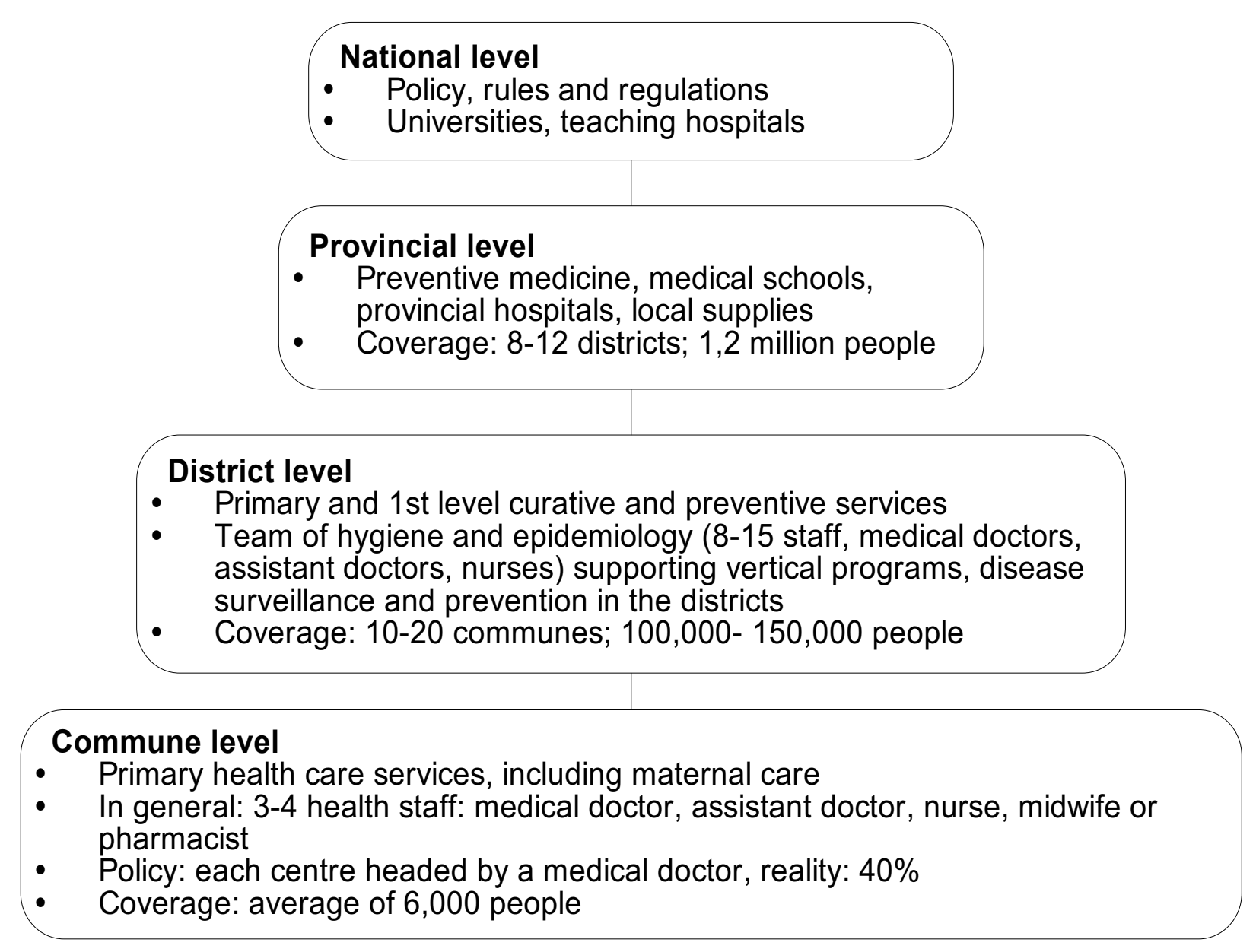

Figure 2

Health system in Viet Nam.

professionals engage in other income generating activities, such as private practice, agriculture etc. [9]. For medical doctors it is for instance, more attractive to remain in the urban areas, where there is a potential market for private practice. It is therefore rather difficult to recruit medical doctors for the facilities in the rural areas and once recruited to retain them. For preventive staff and other staff not being able to start a private practice it is even more difficult to be placed in a rural area, as opportunities for additional income generating activities are limited. However, $80 \%$ of the Vietnamese people live in rural areas and most of the public health staff (84\%) currently works there [8], but often posts are vacant or staff occupying posts is not sufficiently qualified for their job. In addition the difficult working conditions and low salaries are not sufficiently attractive [9].

\section{Methods}

The study was conducted in two provinces in North Viet Nam: Bac Ninh, which is a well developed delta province in the North eastern region and Lao Cai, a less-developed mountainous province in the North western region.

In the two provinces an exploratory qualitative study was conducted. The research team consisted of 6 members: 3 researchers from the Hanoi School of Public Health, two provincial health workers - from the two provinces - and one KIT expert on rapid appraisals.

The team investigated the following aspects of work motivation in the health sector: 
1. Perceptions on what motivates and discourages (demotivates) health workers

2. Perceptions of health workers and managers on Human Resource Management (HRM) tools. The perception on the following HRM tools and their use was explored during the interviews and group discussions:

- continuing education and career development

- communication and relationship among colleagues

- salaries and allowances

- performance management: supervision and staff appraisal

- transfer

- working conditions, such as equipment and transportation

- other activities to retain staff (eg provision of land at a subsidised cost)

3. Perceptions of community members about health workers. Perceptions on the following issues were explored during interviews and group discussions:

- treatment and advice received

- staff attitude during consultations

- criteria for a "good health worker"

- overall performance of health workers and ways for improvement

- current methods used by the community to show appreciation

- suggestions for community methods to influence staff performance and staff motivation

The research team received a training of five days during which they were introduced in the topic of Human Resources for Health and rapid appraisal techniques. During the training, they developed and pre-tested the data collection instruments. Sites and respondents were selected using purposive sampling.

In total fifty-three semi-structured interviews were carried out:
- The organisational level was assessed by interviewing 14 policy makers and managers, including the vice chairman of the people committee, the (deputy) head of the provincial health bureau and the (deputy) head of the district health centre.

- Perceptions of health workers were researched by interviewing 24 health staff working either at district or commune level; 15 men and 9 women. At district level 12 members of the Hygiene and Preventive Medicine team were interviewed and at commune level 12 public health workers.

- Community perceptions were collected through exit interviews, that were conducted in a separate room at the clinic premises with 11 people who visited the health care clinic. All were local people, living in the same community as the health staff.

In addition, eight group discussions were carried out. Four with Public Health workers in the district, each group consisted of 6 people and four discussions with community representatives, each containing 7-8 people.

During the interviews and group discussions, some visualisation methods were used. For instance in order to determine the order of importance for motivating and discouraging factors, health providers identified and weighted the factors they mentioned by using a preference pair ranking matrix [10].

The data were reported and recorded by tape, and were transcribed immediately after the data collection process. The data were summarised on master sheets according to the different research topics for each type of respondent. The researchers discussed the data with each other, and perceptions of interviewees were identified and reported. No major differences emerged between the various districts or at the various levels, nor were there main differences between the points of view of men and women. Therefore perceptions of all interviewed health workers have been combined in the presentation of the findings.

\section{Results}

\section{Profile of the individual respondents}

All policy makers were male. The health staff at district level consisted of 12 people, of which 10 were men and most of the interviewees (7) were medical doctors. At community level, 12 people were interviewed, of whom 7 were women, and the main professions were assistant doctor, nurse or midwife. All of the interviewed staff had a permanent job with the public health sector. 
Table I: What motivates you in your work?

\begin{tabular}{lcc}
\hline Factors for motivation & $\begin{array}{c}\text { District } \\
\text { preventive } \\
\text { staff }(\mathbf{N}=\mathbf{~ 2 )})\end{array}$ & $\begin{array}{c}\text { Commune } \\
\text { health centre } \\
\text { staff }(\mathbf{N}=12)\end{array}$ \\
\hline $\begin{array}{l}\text { Appreciation and support by } \\
\text { managers and colleagues }\end{array}$ & 1 & 1 \\
$\begin{array}{l}\text { People respect me/ appreciate } \\
\text { my work }\end{array}$ & 2 & 2 \\
$\begin{array}{l}\text { Stable job and income } \\
\text { Get more training } \\
\text { Love for the work }\end{array}$ & 3 & 3 \\
\hline
\end{tabular}

Table 2: What discourages you in your work?

\begin{tabular}{lcc}
\hline Discouraging factors & $\begin{array}{c}\text { District }(\mathbf{N}= \\
\text { I 2) }\end{array}$ & $\begin{array}{c}\text { Commune }(\mathbf{N} \\
\mathbf{=} \text { I 2) }\end{array}$ \\
\hline Low income and allowance & 1 & 1 \\
Difficult transportation & 2 & 2 \\
No updated information & 3 & 11 \\
Lack of knowledge & 4 & 3 \\
Heavy work load without plan & 5 & 4 \\
\hline
\end{tabular}

\section{Perceptions on motivating and discouraging factors}

Respondents were asked to mention the main motivating and the main discouraging factors and to order them by comparing these factors two by two. The health providers identified and weighted the factors they mentioned by using a preference matrix. In total for all interviewees only 10 different types of motivating and discouraging factors were mentioned. This allowed the researchers to compare the main motivating and discouraging factors of the health workers and to develop a table showing the average. The order in Table 1 and in Table 2 is the average priority of the first 5 main motivating and discouraging factors for the interviewed health workers.

For commune and district health workers recognition for the work that they do from their managers, colleagues and clients is of great importance, as it has the highest rank. This is illustrated by a quote from a staff member of a district health team:

" I like my job and I am happy that people believe in me. The Village Health Workers trust me, and ask me to help them when needed. I am very proud of that. They are willing to work so it makes me happy. I have retraining and awards every year and the community believes in me. They respect me a lot, so I think I need to work hard for them"
Discouraging factors for health providers at commune and district level are shown in Table 2.

As in many other countries, salaries and allowances are low and not surprisingly mentioned as the main discouraging factor [4]. An illustration from a staff member of a district health team:

"We have very little allowance and salary and the assessment of our boss is not appropriate. It is difficult to execute our plans and we lack communication skills, especially when working in the community".

District health workers mentioned as third discouraging factor a lack of updated information, whereas commune health staff gave this a low score and considered a lack of knowledge an important discouraging factor.

\section{Implementation of HRM}

\section{Continuing education and career development}

Continuing education is by both managers and health personnel translated into "training", and updating knowledge is only really considered when it is through training. Other ways, such as meetings to increase knowledge are not seen as a form of education, although these meetings seem to be organised. Staff also considers books and journals important for upgrading knowledge, but mentions that there is a lack of printed material. There appears to be two types of training, training for a diploma or certificate and training to upgrade knowledge.

Training for a diploma or certificate is organised through the provincial health bureau. According to policymakers and managers, the provincial health bureau and the district health office develop training plans for courses following standards set (targets to be met), but these plans are not always executed due to budget constraints. Selection for training is done by a personnel officer, using criteria as the results of an entry exam, the requirements of the organisation and staff competencies. According to health workers, selection procedures for this type of training are not always understood. This is illustrated by a comment from a staff member at a commune health centre:

"I want to study for Medical Doctor, because I am still young, but I do not know how to get the training. I think I need to work well so my boss will give me the chance to be trained"

These courses count for the $\mathrm{cr}$ of health staff and are therefore considered for a career path. Most people did not express interest in a career. It is not clear why they do not seem interested, probably because "career path" is not a well-known concept in Viet Nam, although it could also be due to a misunderstanding of the question. Most staff 
that was interviewed expressed that they are not interested in changing position, they prefer to stay in their current position, but find upgrading their knowledge regularly through training very important.

Training to upgrade knowledge is, mostly, organised by vertical health programs. According to the managers and the policy makers, this type of training appears to be organised without coordination with the district level. Training by vertical health programs is regularly conducted for the head of district and commune health centres and health workers that are responsible for certain programs. According to managers this type of training does not count for the $\mathrm{cV}$ of health staff. As these courses provide payment of per diems, many health workers perceive participation as an income generating activity. However, health workers feel that not all staff has equal access to these training programs, which is a reason for some to feel that they lack training and income from training.

\section{Communication and relationship among colleagues}

According to managers and policymakers, at all levels regular meetings - often on a monthly basis - are organised to discuss activities and problems. The provincial staff attends three to four meetings a year at district level, and the district level attends meetings at commune health centre level at similar frequency. In addition, they pass information trough official reports and letters. The health staff mentions that the people participating in the meetings do not always distribute the information to their colleagues or subordinates. This results in some people feeling illinformed, as one person commented:

"We discuss and exchange information with VHW and our staff. Concerning information from higher level, it is very little, we don't know much about new policies or regulations. "

This lack of information is considered an especially important discouraging factor at district level.

Relationships at the workplace were in general considered as good, although the researchers had doubts with respect to the willingness of the interviewees to criticise managers and colleagues.

\section{Salaries, allowances and working conditions}

Managers and staff mention that salaries are paid in time and according to official salary scales, but all interviewees consider these salaries as insufficient to cover basic needs for a family. All staff interviewed had a permanent job, which they considered as important as it provides a stable income. In addition to salaries, government allowances are paid for certain tasks, responsibilities or working in certain geographical areas. However, managers men- tioned that the main source of income from the public sector was the vertical programs, that have their own payment levels. The health workers interviewed confirmed this.

In general, health staff considered equipment and drugs to be sufficient, but transportation was mentioned as a problem. In the health facilities health workers often have to use their own (motor) bikes for supervision and outreach. They receive an insufficient reimbursement for fuel.

\section{Performance management}

Managers and policy makers consider supervision as an important tool to control the work of the lower levels and it takes place regularly, although the frequency varies for each level. They consider supervision to be integrated to some extent, as all activities are checked during one single visit. However, according to them, the vertical programs have their own supervision system. Health workers perceived supervision as a control of their work plan with no feedback given. Positive feedback is lacking when the health workers are performing well. This is illustrated by a quotation from a staff member of a preventive health team at district level:

" During supervision of the provincial program such as malaria, the supervisor comes and looks at the record books. If there is something wrong we sit together and fix it but there is no feedback and sometimes I don't know if my work is acceptable or not."

This is important as feedback is one way to show appreciation by managers and colleagues, which was the most important motivating factor for the health workers.

Staff appraisal takes place bi-annually, together with the evaluation of the health facility, as explained by the interviewed managers. Health workers have to assess themselves in writing and assess the team during a meeting. Health staff considers the appraisal not very useful and mainly an administrative process. They had the feeling they could write anything they wanted. As a commune health centre staff remarked:

"We send the appraisal report to the district health centre in a
certain period and in the report we write down what we have
done and we give a self assessment, but we always assess our-
selves positively. The result will affect the assessment of the
group".

Also during performance appraisal appreciation can be shown and therefore can be an important entry point for staff motivation. 
According to managers and policy makers, an additional token of appreciation that is commonly used in Viet Nam is the award system, which is linked to the bi-annual appraisal. Awards (money, certificates or other tokens) are given to people who are assessed as excellent workers. Although its value has decreased over the years, the award system is still appreciated by the health workers. Apart from the award system, strategies to motivate staff are not common.

\section{Perception of the community}

The research showed that the community in the study sites does appreciate and respect their health workers. However, researchers doubt the willingness of the respondents to criticise openly the health workers, as the positive perception in this research seems in contradiction to the low utilisation rate of public health services. An additional complicating factor is that a lot of health workers have a private practice next to their work at the public facility. The community members interviewed appreciate the health workers, but were not asked to distinguish between meeting the workers in the public facilities or in the private facilities. Therefore it is difficult to interpret these data solely for public health providers.

Opportunities for community feedback are provided through a suggestion box in each facility, but those are rarely used. During group discussions, people mentioned ways to show their appreciation through inviting health workers to participate in community activities, and by participating in educational campaigns.

Feedback from the community was for both district and commune health workers the second most important motivating factor and it seems therefore required to find ways to assure community feed back. This appears especially important in rural areas. As health workers in remote areas are less likely to receive supervision, feedback from the community could become an important tool for staff motivation.

\section{Discussion}

The qualitative research provided in-depth information, although not exhaustive as the study had some limitations:

- The team of researchers was familiar with collecting qualitative data, but had limited experience in certain visualisation methods and some team members were not familiar with reporting of qualitative data. Despite the training, this resulted in a loss of data.

- The assessment of the organisation was limited to interviews. The research would have benefited from additional methods to assess the actual implementation of HRM tools, such as observation during meetings, supervision visits and team work, and reading of reports or minutes of meetings

- It appeared that it was not always easy for interviewees to express themselves openly. For instance, managers and policy makers were reluctant to provide their perceptions on the HRM rules and regulations and their implementation. The interviewees provided factual information, but refrained from criticising this. The health workers were more forthcoming with their opinions, but to a limited extent: for instance information on collaboration with colleagues was difficult to retrieve.

- The interviewers found no differences in points of view on motivation between the different levels, nor between men and women. This finding might be correct, but it also might be that the interviewers did not sufficiently probe to identify these differences. In addition during data analysis motivational factors were not analysed according to different professions. It would have been interesting to distinguish between professions as research in Georgia and in Jordan revealed differences in motivation between professional groups [11]. The study revealed a difference in age and in gender in Jordan only.

Despite these limitations, the information obtained allows a general comparison between the motivating and discouraging factors and the perceptions of health workers and managers on Human Resources Management tools that are used to influence functioning of staff.

The results indicate that salaries and working conditions discourage public health workers in rural areas in Viet Nam. The low salaries force them to gain extra income in other ways, either through working in the private sector or through agriculture and animal husbandry. The extent to which this takes place was not researched, but the fact that people earn income through other ways than their regular job is widely accepted and tolerated. There is a risk (not assessed in this study) that the extra work influences the accessibility to and the quality of care provided at the public service, by referring to own clinic, by low attendance in the public health facility etc..

When health workers are present at their work, managers need to find appropriate HRM tools to motivate them to perform well, thus improving quality of care. The results indicate that there is a mismatch between what motivates health workers in rural Viet Nam and the use of HRM tools. Health workers appear to be motivated by recognition and respect from their managers and colleagues and from the community. "Appreciation by boss and colleagues" can be achieved through good relationships at work and by performance management activities such as 
performance appraisals, supervision and access to in-service training. The study showed that the HRM tools that contribute to staff motivation are currently not optimally implemented in rural areas in North Viet Nam; supervision is mainly perceived as a tool for control, appraisals are considered to be for administrative purposes rather than for improving performance and the criteria for selection to training are not always clear.

Feed back from the community appears to be important for health workers in rural Viet Nam as appreciation by the community of the performance of health workers is seen as an important motivating factor. "Appreciation by the community" can be achieved by setting up a mechanism whereby information from the community is collected, through for instance exit interviews and discussions in the community. Currently such a mechanism is lacking in Viet Nam.

Although not many publications exist on motivation of health workers in developing countries, some documents were found that describe motivation from the perspective of health professionals:

- Stilwell found in Zimbabwe as main motivators among nurses "a sense of achievement" and "recognition" [12];

- KIT reported that in Mali the main motivating factors for a variety of health professionals were "being responsible", "work satisfaction (through recognition by boss and colleagues)" and "salaries/ allowances" [13];

- CREDESA described that in Benin health professionals consider "being able to do the work" and "relation with the community" as main motivating factors [14].

These results confirm the importance of achievement, recognition and self fulfilment as motivating factors for health workers. This can be achieved through appreciation by boss, colleagues and/or the community. The results of our research correspond with Herzberg's theory for motivation at the workplace: salaries and working conditions are important to retain staff, but alone are insufficient to lead to better staff performance; recognition and feeling of achievement are more likely to influence staff motivation and therefore their performance. It also shows that although staff is discouraged for various reasons, they still can be motivated to perform. The findings reinforce the importance for managers to select the most appropriate HRM tools for the job, which are different for solving problems of staff retention and staff motivation.

\section{Conclusion}

This study is the first of its kind that asked health workers in rural Viet Nam what motivates them and that looked at their perception on the application of HRM in the field. The study provided information allowing to take into consideration the perception of health workers with respect to motivation policies and its operationalisation. From the findings we can recommend the following:

1. Improvement of staff motivation for better performance

a. Consider both non-financial and financial incentives for health workers. Currently most incentives that are developed are focused on improvement of payment and of working conditions, often with the expectation to improve performance. The study gives an indication that although financial incentives are important, they are not sufficient to motivate personnel to perform better. To achieve better staff motivation, attention should also be paid to incentives that focus on showing appreciation and respect. This can be achieved through performance management (supervision, training, performance appraisal and career development) and feedback from the community. Developing mechanisms that assure regular information on perception of clients on service delivery seem to be important for health workers. This should be used additionally to the existing HRM tools for performance management.

b. Improve implementation of performance management activities as they can contribute to motivation of health staff to work effectively. When non-financial incentives are considered, managers should have the capacity to implement selected performance management activities. Examples of performance management activities that were considered important in the study: supportive supervision, better use of performance appraisal and clearer access to training. These activities can be improved through training (and supervision) of managers and providing tools and guidelines.

c. Establish tailor made performance management systems. If possible, the performance management activities mentioned above should be integrated in a performance management system. This management system is defined as "an interrelated set of policies and practices that, put together, enable the monitoring and enhancement of staff performance" [4]. It implies linking tasks executed by a health worker to supervision, performance appraisal, access to training and career development. Such a system will create an environment in which a health worker can see what she/he has achieved and others can recognise this [3]. A performance management system would facilitate the HRM tasks of health managers.

\section{Development of motivation systems}


a. Involve health workers in the design of a motivation system. Research has shown that managers and workers do not necessarily perceive motivation in the same way [3]. This implies that the perceptions of health workers on motivation have to be known before a system is being proposed. Our experiences show that qualitative research is an appropriate method to explore and describe perceptions of health workers on motivation and HRM issues. It is at the same time a starting point for a participatory approach in designing HRD policies.

b. Ensure that managers clearly understand the impact of different HRM tools on staff retention and staff motivation to perform well. As many managers believe that an increase in salaries will solve the motivation problems, it is important that they understand that though important, improvement in payment will be insufficient to achieve a sustainable better performance. HRM experts should support managers in developing appropriate (and cultural and gender sensitive) HRM tools for staff motivation.

\section{Execution of further studies}

Although the scope of this study was quite ambitious, the results have raised further research questions for policy makers in Viet Nam. Additional areas for study are:

- Organisational assessment of health services through other methods than interviews with managers and health workers (review of documents and reports, observation, data from supervision visits, HRD and HMIS records etc.).

- Community perception on public and private health sector workers

- A comparison of staff motivation in urban areas (as opposed to rural) and in South Viet Nam (as opposed to North Viet Nam)

- Successful mechanisms for community feedback in other countries

Answers to these questions would also make a welcome contribution to the international literature on the use of HRD tools to influence the performance of health workers.

\section{Competing interests}

None.

\section{Authors' contributions}

All authors contributed to and approved the final manuscript.

\section{References}

I. Partnerships for Health Reforms: Primer for policy makers: Health worker motivation and health sector reform [http://www.phrplus.org/ Pubs/pps3.pdf]. accessed: 22-10-2003

2. Franco LM, Bennett $S$ and Kanfer $R$ : Health sector reform and public sector health worker motivation a conceptual framework. Social Science and Medicine 2002, 54:I255- 266.

3. World Health Organization: Training manual on management of human resources for health. Section I, part A. Geneva 1993.

4. Martinez J: Assessing quality, outcome and performance management Geneva: World Health Organization; 200I.

5. Organisation for Economic Co-operation and Development: Public service as an employer of choice 2002 [http://www.oecd.org/dataoecd/ 37/0/1937348.pdf]. London accessed: 22-10-2003

6. Herzberg F: One more time: How do you motivate employees? Harvard Business Review 2003, 8 I (I):87-96.

7. KIT and Hanoi School of Public Health: A study on motivation of health staff in Northern Vietnam Amsterdam: Royal Tropical Institute; 200 I.

8. Ministry of Health of Viet Nam: Health Strategy for the year 2000 to 2020 Hanoi: Ministry of Health; 1996.

9. Wright EP: Vietnam Health Sector Review 1999: Institutional Setting and Human Resources Report Amsterdam: Royal Tropical Institute; 1999.

10. Pretty J, Guijt I, Thompson J and Scoones I: A trainer's guide for Participatory Learning and Action London: International Institute for Environment and Development; 1995.

11. Franco LM, Bennett S, Kanfer R and Stubblebine P: Health Worker Motivation in Jordan and Georgia: a synthesis of results Bethesda: Partnerships for Health Reform, Abt Associates; 2000.

12. Stilwell B: Health worker motivation in Zimbabwe Geneva: World Health Organization; 200I. Unpublished paper

13. Royal Tropical Institute: Etudes auprès des agents socio-sanitaires: la motivation et performance, analyses et recommandations, Rapport final de I' assistance technique à la mission d' appui au développement des ressources humaines au Mali, Tome V Amsterdam; $200 \mathrm{I}$ in press.

14. Alihonou E, Soudé T and Hounyé F: La motivation et la performance du personnel de santé au Bénin New York: United Nations Children's Fund; 1998.

Publish with Biomed Central and every scientist can read your work free of charge

"BioMed Central will be the most significant development for disseminating the results of biomedical research in our lifetime."

Sir Paul Nurse, Cancer Research UK

Your research papers will be:

- available free of charge to the entire biomedical community

- peer reviewed and published immediately upon acceptance

- cited in PubMed and archived on PubMed Central

- yours - you keep the copyright

Submit your manuscript here:

http://www.biomedcentral.com/info/publishing_adv.asp
BioMedcentral 